\title{
Gender Difference in Perceived Social Support and Clinical Anger in Depressed Patients
}

\author{
Uzma Zaidi ${ }^{1}$ \\ ${ }^{\text {I}}$ Associate Professor, Clinical Psychology Track, Department of Health, College of Health and Rehabilitation, \\ Princess Nourah Bint Abdulrahman University, Riyadh, Kingdom of Saudi Arabia)
}

\begin{abstract}
The current study aimed to investigate gender differences in perceived social support and clinical anger among depressed patients. It was hypothesized that there would be significant difference between female and male adult depressed patients in perceived social support and clinical anger. The sample of seventy diagnosed patients was selected from different psychiatry departments of hospitals of Lahore. Multidimensional perceived social support scale and Clinical Anger Scale was used to assess perceived social support and clinical anger in depressed patients respectively. Independent sample t test and Liner regression analysis was calculated for analysis of data. Results showed that there are no significant differences in perceived social support and clinical anger among depressed patients. Findings shows that lower the perceived social support, higher is the clinical anger in depressed patients. The result can helpful for psychologist and other professionals to plan the therapeutic interventions for depressed patients. It will also provide information in family members and friends of the patients to be aware of patient's problems.
\end{abstract}

Keywords: CAS, clinical anger, depression, depressed patients, gender differences, perceived social support

\section{Introduction}

"Depression is not only the most common women's mental health problem but may be more persistent in women than men" (WHO, 2014a). ${ }^{[1]}$

Depression is manifested as depressed mood, anhedonia, disturbance in sleep or appetite, poor concentration, feelings of guilt or low self-worth, and low energy. ${ }^{[2]}$ These symptoms may prolong or intermittent that can result in impaired social and occupational functioning of an individual irrespective of age, gender and ethnic background. According to World Health Organization (2014b) ${ }^{[3]}$, almost 121 million people suffer from depression. Currently, depression is the 2nd cause of DALYs in the age range of 15-44 years for both genders. It is reckoned that depression will take 2nd place in the ranking of DALYs calculated for all ages and both sexes till the year 2020 .

The lifetime risk for Major Depressive Disorder is 5\% to 25\% for women and from 2\% to $12 \%$ for men suffer from this disorder. ${ }^{[2]}$ Woman has diagnosed with depression greater than men due to including reasons social roles, exposed to stresses and physiological and hormonal changes. It has been found that women were more frequently exposed to more of the factors that have been shown to be related to depression, such as of current illness and recent illness. Some investigation has revealed that marriage increased the rate of depression in young women but decreased the rate in young men. ${ }^{[4]}$

In Pakistan, Gadit and Mugford, found different prevalence rate of depression among Lahore (53.4\%), Quetta (43.9\%) and Karachi (35.7\%). Moreover, they found that significant relationship between depression and socio-demographic variable (i.e. middle age, female gender and secondary school level of education). ${ }^{[5]}$ As far as exposure to negative life events there is no significant difference in genders but those women who have no social support are exposed to life events and are more vulnerable than men without support. ${ }^{[6,7]}$ Another study conducted in Karachi, explored significant relationship of extended family system with depression. ${ }^{[8]}$

One important factor in the stress and depression relationship is the amount of social support the individual has available when facing the stress. Holmes, ${ }^{[4]}$ found that social support tends to reduce depression but unfortunately, depressed individuals are less likely to get social support because they are unpleasant to be around. Thus a lack of social support may contribute to the onset of depression and may also serve to maintain the depression. ${ }^{[9]}$ From a societal perspective significant life stress or lack of social support predisposes to the development of Major Depressive disorder. Low social support, both independently and in the face of significant stress also predisposes to depressive disorder. Low Perceived social support that is the extent to which an individual believes himself or herself to lack supportive social networks creates higher risks than any absolute or objective measure. ${ }^{[10]}$

Social support is found to play a vital role in different disorders. ${ }^{[11]}$ Various researches, on depression have identified low perceived support leads directly to depression even in the absence of life events. ${ }^{[9]}$ Social 
support can be defined as the belief that one is cared for and loved, esteemed and valued. ${ }^{[6]}$ Researchers found that social support has relationship with education, psychological well-being , and physical well-being. ${ }^{[12]}$

As a human being and social animal we all live in society. Social support is closely related to social networks, the ties to family, friends, neighbors, colleagues and significant ones. A negatively social network can reinforce thoughts of failure, hopelessness being worthless and without a developed support an individual can develop depression. ${ }^{[13]}$ Moreover social environment, individual characteristics are also related to social support. ${ }^{[14,15]}$ Vollmann and Colleagues, explored interactions between depressed persons and persons within their social network are often characterized by misunderstanding and unsuccessful social support attempts. ${ }^{[16]}$ Perceived social support has adverse effect on major depression and different levels of depression. ${ }^{[17]}$

Another major concept of this study is anger. Anger is a common human emotion. ${ }^{[18]}$ Spielberger,defined anger as an emotion in which feeling diverges in intensity. ${ }^{[19]}$ Sometimes it may be expressed in form of irritation and at times in form of fury or rage. Many professionals have explored the phenomena of anger in past several years. ${ }^{[20,21,22]}$ Clinical anger is a syndrome consisting of various manifestations which varies in intensity from individual to individual. ${ }^{[21,23]}$ Furthermore, outcome of the studies mentioned that there was a relationship between depression and various aspects of clinical anger. ${ }^{[24]}$

Clinical Anger may be exhibited in form of many symptoms such as angry about self, wanting to hurt others, anger about failure, anger about present situation, anger about things, anger about the future, annoying others, hostile feelings, shouting at people, irritated now, angry misery, alienating others. More over there might be fatigue as well as social, work, decision, sleep, thinking, appetite and sexual interference. ${ }^{[25]}$ Over all these symptoms may be categorize in two major classes of somatic symptoms as well as affective symptoms. ${ }^{[26]}$

According to Freudian Psychology, depression is termed as 'anger turned inward'. Then psychodynamic technique focuses on catharsis and finds its root in part. ${ }^{[27]}$ According to Granvold and Beck, cognitive theory has been characterized by a here and now orientation, a belief that thoughts affect feelings, people who are depressed demonstrate a certain set of cognitive distortions (such as negative thinking, black and white thinking, catastrophizing, overgeneralization, selective abstraction, magnification and minimization etc.). ${ }^{[28,29]}$ The first cognitive explanation also revolves around the notion that depressed individuals have negative cognitive sets that leads them to focus their attention on personal shortcomings and other reasons to be depressed, and thinking negative thoughts leads to be depressed (e.g. Beck, 1967; 1976). ${ }^{[26,30]}$ To understand these negative cognitive sets develop and operate; psychologists have applied what we know about human information processing. The information processing approach has three components that is depressed individual are thought to have strong and active associative networks that link together memories, Second, because of their active depression networks, depressed individuals are more likely to attend to depressing things around them, third because of extensive depression networks keep developing, depressed individuals are more likely to recall depressing information. ${ }^{[4]}$

Emil and Coccarofound that depressed patients experienced more anger attacks as compared to normal people. They identified 30-45\% prevalence of anger attacks in depressed population. Though, anger outbursts are not considered as direct feature of depression but patients reported it frequently and it is followed by repentance. ${ }^{[31]}$ Martin and Dahlen, found that cognitive emotion regulation is considered as the predictor of psychological problems. Moreover, they found that self-blame, contemplation, catastrophization, and positive reappraisal were predictors of negative emotions. ${ }^{[32]}$ Another study reported that anger attacks may have adverse effects on the lives of depressed patients as well as their family members. ${ }^{[33]}$ Simultaneously, depressed patients may experience irritability, apprehension, anger expression, trait-anger, psychotic features, and poor quality of life. $^{[34]}$

\section{Objectives}

The ratio of depression is increasing and alarming in Pakistan. Many factors affect depression such as clinical anger, perceived social support, age, gender, education, current stress, insecure attachment, hostility, prevalence amongst other disorders or diseases, difficulties with finance and problematic social interaction. There are fewer researches in Pakistan particularly on clinical anger in depressed patients that's way the present research was conducted to investigate the comparison of gender in perceived social support and clinical anger in depressed patients. The basic aim and objective of current study is to investigate gender difference in depressed patients and to understand the predictive relationship of perceived social support and clinical anger.

\section{Hypotheses}

In the light of above mentioned facts, the following hypotheses are formulated:

1. Perceived social support and clinical anger would be scored high in male patients as compared to female depressed patients.

2. Lower scores on Perceived social support will significantly predicthigher Clinical Anger in Depressed Patients. 


\subsection{Research Design}

\section{Methodology}

The present research utilized comparative research design as it aimed to find out the gender difference in perceived social support and clinical anger in depressed patients.

\subsection{Participants}

A sample for the present study consisted of $(\mathrm{N}=70)$ diagnosed patients of Major Depressive Disorder. Sample was recruited from different psychiatry wards of different hospitals in Lahore that included Mayo Hospital, Services Hospital, Jinnah Hospital, Punjab Institute of Mental Health and Ganga Raam Hospital through purposive sampling technique. Patients were included in the sample who has diagnosed with Major depressive disorder by psychologist and psychiatrist and only hospitalized patients were taken for the present study. Patients were excluded who were diagnosed with Axis II and patients with co-morbidity on Axis-I along with Major Depression.

\subsection{AssessmentMeasures}

Clinical Anger Scale ${ }^{[24]}$ and Multidimensional Perceived Social Support Scale ${ }^{[}$were used.

\subsubsection{Clinical Anger Scale}

The Clinical Anger Scale is a self-report inventory which explicitly measure clinical anger. ${ }^{[2]}$ It comprised of 21 statements that are rated on a 4-point Likert scale ranging from 0-3. The total score of CAS calculated by adding up each item's score (0-63). Higher scores on CAS indicate high level of clinical anger. The internal consistency of the CAS is .94 that indicate reliable instrument for measuring clinical anger. ${ }^{[2]}$ The scale has been translated into Urdu by adapting standard procedure. Psychometric properties was also calculated for the translated version $(\alpha=.75)$ to check the homogeneity of the scale in Pakistani culture.

\subsubsection{Multidimensional Perceived Social Support Scale}

Multidimensional Perceived social support is 12 item scale designated to assess the perception of social support adequacy from three specific sources, the sources being family, friends and significant others. ${ }^{[35]}$ The subject are required to rate their perceptions, of various sources of support, on a 7 point scale ranging from very strongly agree (7) to very strongly disagree( 1$)$. MPSS has good internal (.88) and test-retest (.85) reliability. Internal reliability for the subscales is .91 for the significant others, .87 for family .85 for friends. Test-retest reliability for significant others subscale is .72 , for family subscale is .85 and for friend subscale is $.75 .^{[35]}$

\subsection{Ethical Considerations}

Before using the scales, permission was sought from authors to use and translate scales to use in the study. The scale was translated and its validity and reliability was checked through SPSS. Permission was taken by the Hospital authorities to collect data from their hospital and an authority letter was signed by the hospital authorities. Before administering the scale, participants were clearly explained the purpose and nature of study and written consent was taken from each participant.

\subsection{Procedure}

Formal permission was taken to the concerned psychiatric ward's authorities of hospital. Participants were assured of full confidentiality of all the information obtained from them. A written consent was taken from patients after describing the purpose and nature of the study. Rapport was built before starting the formal procedure. Patients were given Multidimensional perceived social support scale and Clinical Anger scale to complete, they were asked to choose the best option which describes their feelings. It took maximum 15-20 minutes to complete. Questionnaire was filled by the participant.

\subsection{Statistical analysis}

SPSS (statistical package for social sciences) version 17.0 was used to analyze data. Firstly descriptive statistics was used to calculate the frequency and percentage to describe the socio demographic variable. To find out the gender differences Independent t-test was used to check the mean difference of genders on perceived social support and clinical anger. Regression Analysis was computed to find out predictive relationship of the variables of perceived social support and clinical anger in depressed patients. 


\section{Results And Discussion}

Table 1

Independent Sample t-Test for Clinical Anger and Perceived Social Support Scores in Gender in depressed Patients $(\mathrm{N}=$ 70)

\begin{tabular}{lllllll}
\hline Scales & Gender & $n$ & $M$ & $S D$ & $t$ & \\
\hline CAS & Male & 35 & 52.18 & 5.75 & -1.69 & .09 \\
& Female & 35 & 54.83 & 4.00 & -1.81 & .07 \\
MPSSS & Male & 35 & 27.92 & 12.24 & 1.11 & .27 \\
& Female & 35 & 23.88 & 11.43 & 1.12 & .26 \\
$\mathrm{df}=68, \mathrm{p}>.01$ & & & & &
\end{tabular}

Table 2

Pearson Product Moment Correlation between Perceived Social Support and Clinical Anger in Depressed Patients (N=70)

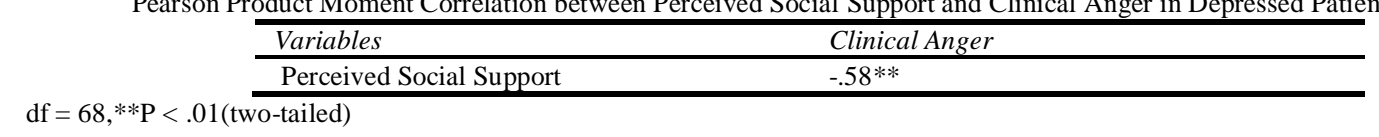

Table 3

Regression Analysis for Variables Predicting Lower the Perceived Social Support, Higher would be the Clinical Anger in Depressed

\begin{tabular}{ccccc} 
& Patients & $\beta$ & $\mathrm{p}$ \\
\hline Predictor Variables & $\mathrm{B}$ & SE B & - & $.000^{* *}$ \\
CAS & 59.95 & 1.57 & -.05 & $.000^{* *}$ \\
\hline MPSSS & -.26 & .05 & -.58 & \\
\hline$=34, \Delta \mathrm{R}^{2}=32, \mathrm{~N}=70, * * \mathrm{p}<01$ (two-tailed) & & &
\end{tabular}

$\mathrm{R}^{2}=.34, \Delta \mathrm{R}^{2}=.32, \mathrm{~N}=70, * * \mathrm{p}<.01$ (two-tailed).

The present research focused to investigate the gender difference on perceived social support and clinical anger in depressed patients. It was first hypothesis that perceived social support and clinical anger would be scored high in male patients as compared to female depressed patients. First hypothesis was that perceived social support and clinical anger would be scored high in female patients as compared to male depressed patients. Independent sample t- test was used to find out the difference of genders on the variables of perceived social support and clinical in depressed patients. Results (Table 1) showed that male and female t-scores on clinical anger scale are $(\mathrm{t}=-1.69)$ and $(\mathrm{t}=-1.82)$ respectively, and male and female $\mathrm{t}$-score on multidimensional perceived social support scale are $(\mathrm{t}=1.11)$ and $(\mathrm{t}=1.12)$ respectively. Thereby the hypothesis is not proven that perceived social support and clinical anger would be scored high in female patients as compared to male depressed patients. The research shows that the clinical anger and perceived social support is independent of gender. This result is not incorporating the previous work. ${ }^{[32]}$ There may be two reasons. Firstly if the sample of male and female would be equal and if it would be the main hypothesis. The results of the research may be changed. Secondly in Pakistani culture, the male are the dominant person in society. They do not tend to express their problems, they express those symptoms differently and may face frustrations. Depression in men, on the other hand, may cause them to be irritable, aggressive, or hostile. Men tend to deny having problems because they are supposed to be strong. Whereas women are not dominant and they share their problems and are less frustrated.

Secondly, it was hypothesized that there would be a significant relationship between perceived social support and clinical anger in depressed patients. Correlation was used to find out the relationship between perceived social support and clinical anger. Liner regression analysis was applied to predict that lower the perceived social support, higher would be the clinical anger in depressed patients. Results (Table 2) shows that perceived social support $(\mathrm{r}=-.58 ; \mathrm{p}<.01)$ and clinical anger $(\mathrm{r}=-.58 ; \mathrm{p}<.01)$ are negatively correlated in depressed patients. Thereby the hypothesis is partially proven that there is significant relationship between perceived social support and clinical anger in depressed patients. Results (Table 3 ) shows that perceived social support $(\mathrm{p}=.000 ; \mathrm{p}<.01)$ and clinical anger $(\mathrm{p}=.000 ; \mathrm{p}<.01)$ are predictor of depressed patients. Thereby the hypothesis is proven that there is significant predictive relationship between perceived social support and clinical anger in depressed patients and lower would be the perceived social support, higher would be the clinical anger in depressed patients. The result is consistent with previous studies which suggested that the depressed patient with high clinical anger have low perceived social support. ${ }^{[36]}$ Liner regression was used to find lower would be the perceived social support; higher would be the clinical anger in depressed patients. Results (Table 3) showed that perceived social support and clinical anger are predictors of depressed patients. The results are significant which proved that lower would be the perceived social support, higher would be the clinical anger in depressed patients.

Hence the people with lower perceived social support and high clinical anger are more vulnerable to depression and other health problems. Perceived social support and clinical anger is predictor of depressed patients. Clinical anger is anger when the person is out of control. Clinical anger consist of two factors i.e., affective and somatic. Both factors have relationship with depression. In the present investigation it was felt that 
further insight into the nature of depression could be gained by examining the particular types of factors uniquely associated with depression, especially those factors dealing with both major life events and everyday hassles.

\section{Conclusion}

The findings can helpful for psychologist and other professionals to plan the therapeutic interventions for depressed patients. It will also provide information in family members and friends of the patients to be aware of patient's problems. Psycho-education will be beneficial for family members of the patients. Results can be demonstrated to psychiatric population. Seminars and therapeutic intervention should be conducted to make the psychiatric population aware the problems of social support and clinical anger and telling them strategies to overcome these problems.

However, the present research has some limitations. The sample size was small, so the results cannot be generalized. During data collection focus was on hospitalized patients. Only Major depressive disorder patients were taken. In order to overcome these limitation some of the suggestions are presented here for future study. The sample size should increase so that we can generalize our results back to the population from which sample was taken. Instead of perceived social support some other measures could be used to understand received support or actual support available from family members or friends. Studies can also be conducted to find out gender difference in perceived social support and clinical anger with other disorders.

\section{Acknowledgements}

I am thankful to the authors for giving me permission to use the concerned scales for the purpose of data collection.I would like to thank the Heads of hospitals and Psychiatry wards who gave me permission to collect data from their hospitals. I am also grateful to patients who participated in this study.

\section{References}

[1]. World Health Organization. Gender and women's mental health. Gender disparities and mental health: The Facts. (2014a). Retrieved on April, 2014 from http://www.who.int/mental_health/prevention/genderwomen/en/

[2]. American Psychological Association. Diagnostic and statistical manual of mental disorders,5 (Arlington, VA: American Psychiatric Association, 2013).

[3]. World Health Organization. Mental Health: Depression. (2014b). Retrieved on April,2014 from http://www.who.int/mentalhealth/management/depression/definition/en/

[4]. D.A. Holmes, Abnormal, clinical \& forensic psychology. (Harlow: Pearson, 2010).

[5]. A. A. M.Gadit, and G. Mugford, (2007). Prevalence of depression among households in three capital cities of Pakistan: Need to revise the mental health policy. PLoS ONE, 2(2),2007, e209.

[6]. O. S. Dalgard, C. Dowrick, V. Lehtinen, J. L. Vazquez-Barquero, P. Casey, G. Wilkinson, J. L. Ayuso-Mateos, H. Page, G. Dunn, and ODIN Group, Negative life events, social support and gender difference in depression: a multinational community survey with data from the ODIN study. Social Psychiatry and Psychiatric Epidemiology, 41(6), 2006, 444-51.

[7]. M. Piccinelli, and G. Wilkinson, Gender differences in depression: Critical review. British Journal of Psychiatry, 177, 2000, 486492.

[8]. B. S. Ali., M. H. Naeem, S. Rahbar, A.. L.. Tareen, A. Gul, and L. Samad,Prevalence of and factors associated with anxiety and depression among women in a lower middle class semi-urban community of Karachi, In H. Naqvi, Depression in Pakistan: An epidemiological critique. Journal of Pakistan Psychiatric Association, 4 (1), 2007, 1-10.

[9]. K. S.Dobson, and D. J. A. Dozois, Risk factors in depression. (Oxford, England: Elsevier, 2008).

[10]. M. D.Feldman, and J. F. Christensen, (2014). Behavioral medicines: a guide for clinical practice 3. (McGraw-Hill Education: USA, 2014, p.202).

[11]. A. L. W.Tierney, and J. S. V. Wall, The effects of social support and coping on the relationship between social anxiety and eating disorders. Eating Behaviors, 11 (2), 2010, 85-91.

[12]. J. R.Bloom, S. L Stewart, M. Johnston, P. Banks, and P. Fobair, Sources of support and the physical and mental well-being of young women with breast cancer. Social Science \& Medicine, 53 (11), 2001, 1513-1524

[13]. T. D.Wade, and K. S. Kendler, The relationship between social support and major depression: Cross-sectional, longitudinal, and genetic perspectives. Journal of Nervous and Mental Disease, 188, 2000, 251-258.

[14]. H. Patrick, A. M.Ryan, and A.Kaplan, Early Adolescent's perceptions of the classroom social environment, motivational beliefs and engagement. Journal of Educational Psychology, 99 (1), 2007, 83-98.

[15]. M. J. Schroevers, A. V.Ranchor, and R.Sanderman, The role of social support and self-esteem in the presence and course of depressive symptoms by comparison of depressive and individual from the general population. Social Science \& Medicine, 57 (2), 2003, 375-385.

[16]. M.Vollmann, M.Scharloo, C. Salewski, A. Dienst, K. Schonauer, B. Renner, Illness representations of depression and perceptions of the helpfulness of social support: Comparing depressed and never-depressed persons. Journal of Affective Disorders, 125 (1-3), 2010, 213-20.

[17]. U.Leskela H. Rytsala, E. Komulainen, T. Melartin, P. Sokero, P. Mielonen, and E. Isometsa, The influence of adversity and perceived social support on the outcome of major depressive disorder in subjects with different levels of depressive symptoms. Psychological Medicine, 36 (6), 2006, 779-88.

[18]. J. Lacan, Aggressively in psychoanalysis. In Écrits: A selection, trans. A. Sheridan, (New York: W. W. Norton), 1977, pp. 8-29.

[19]. C.D. Spielberger, (1988). Professional manual for the State-Trait anger expression inventory. (Odessa FL: Psychological Assessment resources, 1988).

[20]. J. R. Averill, Studies on anger and aggression. In W. E. Snell, Progress in the study ofphysical and psychological health. (Cape Girardeau, MO: Snell Publications, 2002). 
[21]. M. K.Biaggio, and R. D. Maiuro, Recent advances in anger assessment. In W. E. Snell, Progress in the study ofphysical and psychological health. (Cape Girardeau, MO: Snell Publications, 2002).

[22]. S. Feshbach, Reconceptualization of anger: Some research perspectives. In W. E. Snell, Progress in the study ofphysical and psychological health. (Cape Girardeau, MO: Snell Publications, 2002).

[23]. C. D. Spielberger, E. H. Jacobs, S. Russell, and R. S. Crane, Clinical Anger: Construct, measurement reliability, validity. In W. E., Jr. Snell, Progress in The Study of Physical and Psychological Health. (Cape Girardeau, MO: Snell Publications. 2002).

[24]. W. E., Jr. Snell, Progress in The Study of Physical and Psychological Health. (Cape Girardeau, MO: Snell Publications. 2002).

[25]. D. L.Cox, S. D.Stabb, and K. H.Bruckner, Women's anger clinical and developmental perspective. (U.S.A: BraunBrumfield,1999, p. 93).

[26]. A. T. Beck, Depression: Causes and treatment. (Philadelphia: University of Pennsylvania Press, 1967).

[27]. A. R. Robberts, and G. J. Greene, Social workers' desk reference. (New York: Oxford University Press, 2002).

[28]. D. K. Granvold, Depression: Integration of Psychodynamic and cognitive behavioral therapies. In A. R., Robberts and G. J. Greene, Social Workers' desk reference. (New York: Oxford University Press, 2002).

[29]. A. T. Beck, Depression: Integration of Psychodynamic and Cognitive Behavioral Therapies. In A. R., Robberts and G. J. Greene, Social Workers' Desk Reference. (New York: Oxford University Press, 2002, p. 353).

[30]. A. T. Beck, Cognitive Therapy and the Emotional Disorders. (Penguin Books, 1976).

[31]. F.Emil, and E. F. Coccaro, Aggression : Psychiatric assessment and treatment. (U.S.A : Marcel Dekker, 2003).

[32]. R. C. Martin, and E. R. Dahlen, Cognitive emotion regulation in the prediction of depression, anxiety, stress, and anger. Personality and Individual Differences, 39 (7), 2005, 1249-1260.

[33]. N. Painuly, P. Sharan, and S. K. Mattoo, Antecedents, concomitants and consequences of anger attacks in depression. Psychiatry Research , 153(1), 2006, 39-45.

[34]. A. Troisi, and A. D'Argenio, The relationship between anger and depression in a clinical sample of young men: the role of ins ecure attachment. Journal of Affective Disorders, 79 (1-3), 2004, 269-272.

[35]. G.D.Zimet, N.W.Dahlem, S.G. Zimet, and G.K. Farley, The multidimensional scale of perceived social support. Journal of Personality Assessment, 52,1988, 30-41.

[36]. O. A.O'Neill, R. J.Vandenberg, D. M.DeJoy, and M. G. Wilson, Exploring relationships among anger, perceived organizational support, and workplace outcomes. Journal of Occupational Health Psychology, 14 (3), 2009, 318-333. 